\title{
Optimal cutoff values for anthropometric indices of obesity as discriminators of metabolic abnormalities in Korea: results from a Health Examinees study
}

Sooyoung Cho ${ }^{1}$, Aesun Shin ${ }^{1,2^{*}}$ (D) Ji-Yeob Choi ${ }^{2,3}$, Sang Min Park ${ }^{3,4,5}$, Daehee Kang ${ }^{1,3}$ and Jong-Koo Lee , $5,6,7^{-}$

\begin{abstract}
Background: Obesity is well known as a risk factor for cardiovascular disease. We aimed to determine the performance of and the optimal cutoff values for obesity indices to discriminate the presence of metabolic abnormalities as a primary risk factor for cardiovascular diseases in a Health Examinees study (HEXA).

Methods: The current study analyzed 134,195 participants with complete anthropometric and laboratory information in a Health Examinees study, consisting of the Korean population aged 40 to 69 years. The presence of metabolic abnormality was defined as having at least one of the following: hypertension, hyperglycemia, or dyslipidemia. The area under the receiver operating characteristic curve (AUC) and 95\% confidence intervals (Cls) were calculated for body mass index, waist to hip ratio, waist to height ratio, waist circumference, and conicity index.

Results: The AUC of metabolic abnormalities was the highest for waist-to-height ratio (AUC [95\% Cls], 0.677 [0.6720.683] among men; 0.691 [0.687-0.694] among women), and the lowest for the $C$ index (0.616 [0.611-0.622] among men; 0.645 [0.641-0.649] among women) among both men and women. The optimal cutoff values were $24.3 \mathrm{~kg} /$ $\mathrm{m}^{2}$ for the body mass index, 0.887 for the waist-to-hip ratio, 0.499 for the waist-to-height ratio, $84.4 \mathrm{~cm}$ for waist circumference and $1.20 \mathrm{~m}^{3 / 2} / \mathrm{kg}^{1 / 2}$ for the conicity index among men, and $23.4 \mathrm{~kg} / \mathrm{m}^{2}$ for the body mass index, 0.832 for the waist-to-hip ratio, 0.496 for the waist-to-height ratio, $77.0 \mathrm{~cm}$ for the waist circumference and 1.18 $\mathrm{m}^{3 / 2} / \mathrm{kg}^{1 / 2}$ for the conicity index among women.

Conclusion: The waist-to-height ratio is the best index to discriminate metabolic abnormalities among middleaged Koreans. The optimal cutoff of obesity indices is lower than the international guidelines for obesity. It would be appropriate to use the indices for abdominal obesity rather than general obesity and to consider a lower level of body mass index and waist circumference than the current guidelines to determine obesity-related health problems in Koreans.
\end{abstract}

Keywords: Obesity; hypertension, Hyperglycemia, Dyslipidemia, Sensitivity and specificity, Area under the curve

\footnotetext{
* Correspondence: shinaesun@snu.ac.kr

${ }^{1}$ Department of Preventive Medicine, Seoul National University College of Medicine, Seoul, Republic of Korea

${ }^{2}$ Cancer Research Institute, Seoul National University, Seoul, Republic of Korea

Full list of author information is available at the end of the article
}

C The Author(s). 2021 Open Access This article is licensed under a Creative Commons Attribution 4.0 International License, which permits use, sharing, adaptation, distribution and reproduction in any medium or format, as long as you give appropriate credit to the original author(s) and the source, provide a link to the Creative Commons licence, and indicate if changes were made. The images or other third party material in this article are included in the article's Creative Commons licence, unless indicated otherwise in a credit line to the material. If material is not included in the article's Creative Commons licence and your intended use is not permitted by statutory regulation or exceeds the permitted use, you will need to obtain permission directly from the copyright holder. To view a copy of this licence, visit http://creativecommons.org/licenses/by/4.0/. The Creative Commons Public Domain Dedication waiver (http://creativecommons.org/publicdomain/zero/1.0/) applies to the data made available in this article, unless otherwise stated in a credit line to the data. 


\section{Background}

Obesity has emerged as a public concern worldwide, as its incidence has been steadily increasing [1]. The Global Burden of Disease Study reported that the estimated worldwide prevalence rates of obesity were 28.8 to $36.9 \%$ in men and 29.8 to $38.0 \%$ in women between 1980 and 2013 [2], and global death attributable to obesity rapidly increased more than doubling between 1990 and 2017 [3]. People with obesity are at increased risk for cardiovascular diseases, type 2 diabetes, certain cancers, and premature death $[4,5]$.

Body mass index is widely used for defining general obesity. The World Health Organization (WHO) recommended a lower cutoff point of body mass index for Asian populations than for Western populations [6], and it reflects the realization that adverse health is associated with a lower body mass index than the WHO criteria for Western countries [7]. Furthermore, recent studies have concluded that waist circumference, waist-to-hip ratio, and waist-to-height ratio better discriminate obesityrelated metabolic abnormalities than body mass index [8-10]. Therefore, it is necessary to identify the optimal cutoff of obesity indices and to assess the discriminative power for obesity-related health problems in representative Asian populations. In this study, we aimed to evaluate the performance of obesity indices and to determine the optimal cutoff values for obesity indices to discriminate the presence of metabolic abnormalities in middleaged Koreans. We comparatively investigated five obesity indices, including body mass index, waist circumference, waist-to-hip ratio, waist-to-height ratio, and conicity index, in the analyses.

\section{Method}

\section{Study population}

The Health Examinees (HEXA) study is a part of the Korea Genome Epidemiology Study (KoGES) [11]. National Health Insurance Corporation (NHIC) covers the entire Korean population for general health screening, and beneficiaries aged over 40 years can biannually receive screening through the national health examination program [12]. Participants in the HEXA study were prospectively recruited from 2004 to 2013 at 38 health examination centers and training hospitals located in 8 regions based on the infrastructural advantage of the national health checkup services funded by the Korea Centers for Disease Control and Prevention [11].

Figure 1 shows the flow chart of the study population. We included HEXA participants aged 40 to 69 years in the analyses and restricted them to Health ExamineesGem (HEXA-G) participants who were defined as follows: we excluded (1) 8 sites $(n=9370)$ that only participated in the pilot study years 2004-2006, (2) 8 sites $(n=$ 12,205) that did not meet the HEXA biospecimen quality control criteria (i.e., different testing protocols), and (3) 5 sites $(n=8799)$ that had participated in the study for less than 2 years. A total of 139,348 participants were included in the HEXA-G data. Among HEXA-G participants, we excluded 1391 participants who had no information on anthropometric measurements of height, weight, waist circumference, and hip circumference. An additional 3762 participants had no information on blood pressure or biochemical measurements of the blood specimen, such as fasting glucose, triglyceride, and high-density lipoprotein. We conducted all analyses among the 134,195 participants who remained after exclusion.

\section{Data collection}

Participants were interviewed by trained interviewers and responded to a structured questionnaire on general characteristics and past medical history. Biochemical assessments and anthropometric measurements were also conducted for all participants. Blood specimens were taken after $8 \mathrm{~h}$ of fasting at enrollment and were transported to the clinical laboratory for blood tests using plasma to examine the levels of glucose, triglyceride, and high-density lipoprotein. Height was measured using digital freestanding stadiometers (BSM, InBody Co, Seoul, Korea) with the participants' head in the Frankfort horizontal plane and was read up to one decimal place. Weight was measured using digital scales (BSM, InBody Co, Seoul, Korea) in units of $10 \mathrm{~g}$. Waist and hip circumferences were obtained with a measuring tape in a horizontal plane and were read up to one decimal place. In detail, waist circumference was measured at the midpoint between the lower margin of the last palpable rib and the top of the iliac crest, and hip circumference was measured around the widest part of the buttocks.

Systolic and diastolic blood pressure values were manually measured using a stethoscope and mercury sphygmomanometer on one arm in the sitting position according to the standard operating procedure by trained medical staff. Blood pressure was measured at least twice, and the second blood pressure measurement was taken at least $1 \mathrm{~min}$ after the first measurement. If the difference between the two records of blood pressure was more than $5 \mathrm{mmHg}$, additional measurements were taken until the last two records of blood pressure were similar. Then, the last two records of blood pressures were recorded. Blood pressure was measured in both arms and was remeasured if the difference in blood pressure between both arms was more than $10 \mathrm{mmHg}$. Blood pressure was measured on the other arm only if there were arm injuries, previous breast surgery, venous or arterial tubes, or plaster bandages. We determined blood pressure as the average of the two readings. 


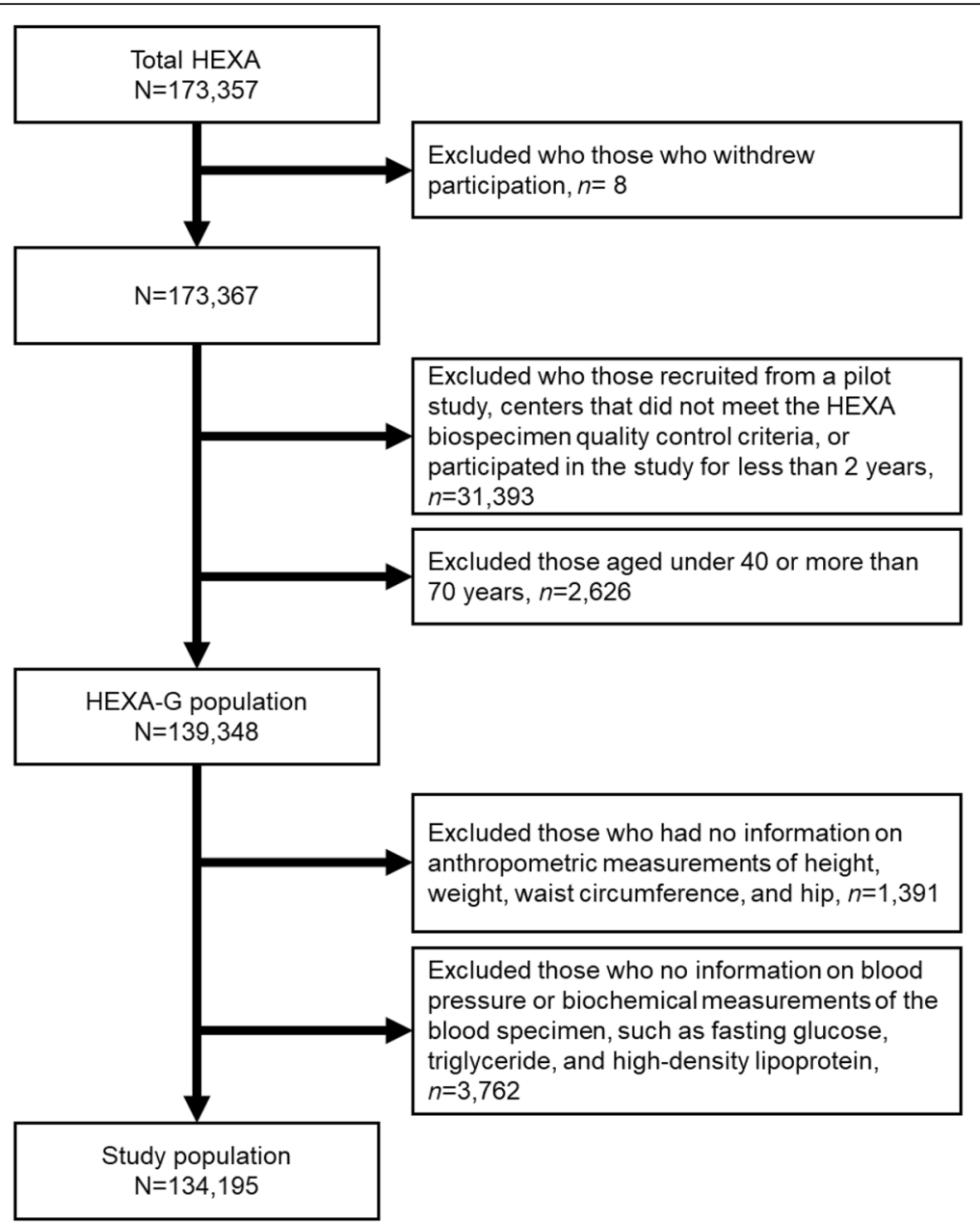

Fig. 1 Inclusion and exclusion criteria of the study population

\section{Definition of terms}

Body mass index, waist circumference, waist-to-hip ratio, and waist-to-height ratio were calculated using directly measured anthropometric values. Additionally, we considered the conicity index as a measure of central adiposity with the equation below [13].

$$
\text { Conicity index }=\frac{\text { waist circumference }(m)}{0.109 \times \sqrt{\frac{\text { weight }(\mathrm{kg})}{\text { height }(\mathrm{m})}}}
$$

Participants meeting at least one of the following criteria were considered to have metabolic abnormalities: defined hypertension [14], those who had systolic blood pressure higher than $140 \mathrm{mmHg}$ or diastolic blood pressure higher than $90 \mathrm{mmHg}$, or those who reported taking antihypertensive medication; hyperglycemia [15], those who had a fasting blood glucose higher than 126 $\mathrm{mg} / \mathrm{dL}$ or who reported taking antidiabetic medication; and dyslipidemia, those who had a triglyceride level higher than $150 \mathrm{mg} / \mathrm{mL}$, high-density lipoprotein cholesterol lower than $40 \mathrm{mg} / \mathrm{dL}$, or those who reported taking medication for dyslipidemia. Low-density lipoprotein cholesterol is commonly used for diagnoses of dyslipidemia, but low-density lipoprotein cholesterol was not directly measured from blood samples. Therefore, we defined dyslipidemia using the levels of triglycerides and high-density lipoprotein cholesterol.

\section{Statistical analyses}

We calculated the means and standard deviations for demographic, anthropometric, blood pressure, and biochemical characteristics. The inclusion of a large population in this study would reduce the meaningfulness of statistical significance for differences in the general characteristics between sexes. For this reason, we did not present a $p$-value in the descriptive analysis of Tables 1 and 2. Receiver operating characteristic (ROC) curves were plotted for obesity indices to identify the best obesity index that discriminates the presence of metabolic abnormalities. The area under the receiver 
Table 1 Anthropometric indices of obesity and metabolic characteristics among HEXA-G participants by sex, mean \pm standard deviation

\begin{tabular}{lll}
\hline & Men $(\boldsymbol{N}=\mathbf{4 5 , 0 5 2})$ & Women $(\boldsymbol{N}=\mathbf{8 9}, \mathbf{1 4 3})$ \\
\hline Age, years & $53.6 \pm 8.38$ & $52.3 \pm 7.76$ \\
Height, $\mathrm{cm}$ & $168.8 \pm 5.74$ & $156.5 \pm 5.26$ \\
Weight, $\mathrm{cm}$ & $69.6 \pm 9.23$ & $57.9 \pm 7.66$ \\
Waist circumference, $\mathrm{cm}$ & $85.7 \pm 7.52$ & $78.3 \pm 8.17$ \\
Hip circumference, $\mathrm{cm}$ & $96.0 \pm 5.64$ & $93.5 \pm 5.69$ \\
Body mass index, $\mathrm{kg} / \mathrm{m}^{2}$ & $24.4 \pm 2.75$ & $23.6 \pm 2.94$ \\
Waist-to-hip ratio & $0.89 \pm 0.05$ & $0.84 \pm 0.06$ \\
Waist-to-height ratio & $0.51 \pm 0.04$ & $0.50 \pm 0.06$ \\
Conicity index, $\mathrm{m}^{3 / 2} / \mathrm{kg}^{1 / 2}$ & $1.23 \pm 0.06$ & $1.18 \pm 0.08$ \\
Systolic blood pressure, $\mathrm{mmHg}$ & $125.7 \pm 14.35$ & $120.6 \pm 15.17$ \\
Diastolic blood pressure, $\mathrm{mmHg}$ & $78.7 \pm 9.68$ & $74.7 \pm 9.66$ \\
Fasting serum glucose level, $\mathrm{mg} / \mathrm{dL}$ & $99.3 \pm 24.28$ & $92.7 \pm 18.47$ \\
Triglyceride, mg/dL & $151.4 \pm 111.41$ & $112.5 \pm 74.18$ \\
High-density lipoprotein cholesterol, $\mathrm{mg} / \mathrm{dL}$ & $49.4 \pm 12.09$ & $56.1 \pm 12.80$
\end{tabular}

operating characteristic curves (AUCs) was used as a summary measure of accuracy to evaluate the performance of obesity indices for the discrimination of participants with metabolic dysfunctions. Youden's J statistics [16] were used to determine the optimal cutoff values for the obesity indices. Youden's index was calculated using the equation below.

$$
\text { Youden' } J \text { statistics }=\text { sensitivity }+ \text { specificity }-1
$$

We considered the optimal cutoff values at the corresponding value for the maximum Youden index. All statistical analyses were stratified by sex. We analyzed data using SAS version 9.4 (SAS Institute Inc., Cary, NC, USA) for the calculation of optimal cutoff points and $R$ software version 3.6.3 [17] for the calculation of the AUCs.

Table 2 Prevalence of metabolic abnormalities among HEXA-G participants by sex

\begin{tabular}{lll}
\hline & Men & Women \\
\hline Hypertension $^{\mathrm{a}}, \mathrm{n}(\%)$ & $15,310(34.0)$ & $21,386(24.0)$ \\
Hyperglycemia $^{\mathrm{b}}, \mathrm{n}(\%)$ & $5196(11.5)$ & $5319(6.0)$ \\
Dyslipidemiac $^{\mathrm{a}}$, n (\%) & $21,794(48.4)$ & $39,768(44.6)$ \\
Metabolic abnormalities $^{\mathrm{d}}, \mathrm{n}(\%)$ & $29,605(65.7)$ & $49,680(55.7)$
\end{tabular}

${ }^{\mathrm{a} S y s t o l i c}$ blood pressure higher than $140 \mathrm{mmHg}$, diastolic blood pressure higher than $90 \mathrm{mmHg}$ or those who reported taking antihypertensive medication

${ }^{\mathrm{b}}$ Fasting glucose higher than $126 \mathrm{mg} / \mathrm{dL}$ or those who reported taking antidiabetic medication

'Triglyceride higher than $150 \mathrm{mg} / \mathrm{mL}$, high-density lipoprotein cholesterol lower than $40 \mathrm{mg} / \mathrm{dL}$ or those who reported taking medication for dyslipidemia

${ }^{d}$ Having at least one of the aforementioned factors

\section{Results}

The anthropometric indices of obesity and metabolic characteristics are presented in Table 1 . The mean ages were 53.6 years for men and 52.3 years for women. Men had higher values than women for all anthropometric, blood pressure, and biochemical characteristics, except for high-density lipoprotein cholesterol. Table 2 describes the prevalence of hypertension, diabetes, hyperglycemia, dyslipidemia, and metabolic abnormalities among HEXA-G participants by sex. More than half of the participants had at least a single metabolic abnormality of diabetes, hypertension, or dyslipidemia in both men (65.7\%) and women (55.7\%). The prevalence of metabolic abnormalities was higher in men than in women. Among the components of metabolic abnormalities, the prevalence was the lowest for hyperglycemia (11.5\% for men; $6.0 \%$ for women) and highest for dyslipidemia ( $48.4 \%$ for men; $44.6 \%$ for women).

The AUCs of the obesity indices associated with metabolic abnormalities and their components are shown in Table 3. Among men, the highest AUCs to discriminate metabolic abnormalities were obtained in the waist-toheight ratio (AUC $[95 \%$ confidence intervals], 0.677 [0.672-0.683]), followed by the waist circumference (0.671 [0.666-0.677]), body mass index (0.667 [0.661$0.672])$ and the waist-to-hip ratio (0.656 [0.650-0.661]) and conicity index (0.616 [0.611-0.622]); the AUCs of the waist-to-hip ratio and the conicity index were significantly lower than those of the waist-to-height ratio, the waist circumference, and the body mass index. Among women, the highest AUCs were obtained in the waistto-height ratio $(0.691[0.687-0.694])$, followed by the waist-to-hip ratio $(0.681[0.677-0.684])$, the waist 
Table 3 Areas under the receiver operating characteristic curves and the corresponding 95\% confidence intervals of obesity indices associated with metabolic abnormalities and their components among HEXA-G participants by sex

\begin{tabular}{|c|c|c|}
\hline & Men & Women \\
\hline \multicolumn{3}{|l|}{ Hypertension $^{\mathrm{a}}$} \\
\hline Body mass index & $0.629(0.624-0.635)$ & $0.668(0.664-0.672)$ \\
\hline Waist circumference & $0.629(0.624-0.635)$ & $0.671(0.667-0.675)$ \\
\hline Waist-to-hip ratio & $0.617(0.612-0.623)$ & $0.665(0.661-0.669)$ \\
\hline Waist-to-height ratio & $0.646(0.640-0.651)$ & $0.687(0.683-0.691)$ \\
\hline Conicity index & $0.593(0.587-0.598)$ & $0.635(0.631-0.639)$ \\
\hline \multicolumn{3}{|l|}{ Hyperglycemia ${ }^{\mathrm{b}}$} \\
\hline Body mass index & $0.570(0.562-0.579)$ & $0.642(0.634-0.649)$ \\
\hline Waist circumference & $0.605(0.597-0.613)$ & $0.683(0.675-0.690)$ \\
\hline Waist-to-hip ratio & $0.636(0.629-0.644)$ & $0.715(0.708-0.721)$ \\
\hline Waist-to-height ratio & $0.616(0.608-0.624)$ & $0.693(0.686-0.700)$ \\
\hline Conicity index & $0.611(0.603-0.619)$ & $0.674(0.667-0.681)$ \\
\hline \multicolumn{3}{|l|}{ Dyslipidemiac } \\
\hline Body mass index & $0.645(0.640-0.650)$ & $0.636(0.632-0.639)$ \\
\hline Waist circumference & $0.645(0.640-0.651)$ & $0.648(0.644-0.652)$ \\
\hline Waist-to-hip ratio & $0.625(0.620-0.630)$ & $0.651(0.647-0.654)$ \\
\hline Waist-to-height ratio & $0.641(0.636-0.646)$ & $0.653(0.649-0.657)$ \\
\hline Conicity index & $0.587(0.582-0.593)$ & $0.618(0.614-0.622)$ \\
\hline \multicolumn{3}{|l|}{ Metabolic abnormalities $^{d}$} \\
\hline Body mass index & $0.667(0.661-0.672)$ & $0.668(0.665-0.672)$ \\
\hline Waist circumference & $0.671(0.666-0.677)$ & $0.680(0.677-0.684)$ \\
\hline Waist-to-hip ratio & $0.656(0.650-0.661)$ & $0.681(0.677-0.684)$ \\
\hline Waist-to-height ratio & $0.677(0.672-0.683)$ & $0.691(0.687-0.694)$ \\
\hline Conicity index & $0.616(0.611-0.622)$ & $0.645(0.641-0.649)$ \\
\hline
\end{tabular}

asystolic blood pressure higher than $140 \mathrm{mmHg}$, diastolic blood pressure higher than $90 \mathrm{mmHg}$ or those who reported taking antihypertensive medication

${ }^{\mathrm{b}}$ fasting glucose higher than $126 \mathrm{mg} / \mathrm{dL}$ or those who reported taking antidiabetic medication

'triglyceride higher than $150 \mathrm{mg} / \mathrm{mL}$, high-density lipoprotein cholesterol lower than $40 \mathrm{mg} / \mathrm{dL}$ or those who reported taking medication for dyslipidemia

${ }^{\mathrm{d}}$ Having at least one of the aforementioned factors

circumference (0.680 [0.677-0.684]), the body mass index $(0.668[0.665-0.672])$ and the conicity index (0.645 [0.641-0.649]). Women had higher AUCs associated with metabolic abnormalities for all obesity indices than men.

Table 4 shows the optimal cutoff values of obesity indices for metabolic abnormalities. Optimal cutoff values to discriminate metabolic abnormalities were $24.3 \mathrm{~kg} / \mathrm{m}^{2}$ for the body mass index, $84.4 \mathrm{~cm}$ for the waist circumference, 0.887 for the waist-to-hip ratio, 0.499 for the waist-to-height ratio and $1.20 \mathrm{~m}^{3 / 2} / \mathrm{kg}^{1 / 2}$ for the conicity index for men and $23.4 \mathrm{~kg} / \mathrm{m}^{2}$ for the body mass index, $77.0 \mathrm{~cm}$ for the waist circumference, 0.832 for the waist- to-hip ratio, 0.496 for the waist-to-height ratio and 1.18 $\mathrm{m}^{3 / 2} / \mathrm{kg}^{1 / 2}$ for the conicity index for women.

\section{Discussion}

Using the baseline data from a large community-based cohort study, we examined the discriminative performance of obesity indices for the presence of metabolic abnormalities by calculating the AUCs. The highest discriminative power to discriminate metabolic abnormalities was shown for the waist-to-height ratio among both men and women. Compared with body mass index, as an index of general obesity, indices for abdominal obesity (i.e., waist circumference, waist-to-hip ratio and waist-to-height ratio) show better performance in discriminating abnormal metabolic status. Among the indices for abdominal obesity, there was no significant difference in the discriminative power to the presence of metabolic abnormalities between waist circumference and waist-to-hip ratio.

We also determined the optimal cutoff values of obesity indices in the present study. The optimal cutoff of the waist-to-height ratio for all factors of metabolic abnormalities was approximately 0.5 for both men and women, which is consistent with the results from a previously published systematic review [18]. The optimal cutoff values of the waist circumference, waist-to-hip ratio and body mass index were different for each factor of metabolic abnormalities.

Although body mass index is widely used to determine healthy weight, abdominal obesity indices have been reported to be better tools to discriminate the presence of metabolic abnormalities in Asians [19-23], Australians [24], and Americans [25]. A previous prospective cohort study on the obesity index and metabolic dysfunction also showed that abdominal obesity indices, especially the waist-to-hip ratio, were a better predictor than body mass index for developing multiple metabolic risk factors in the Korean population [26].

A meta-analysis from previously published crosssectional or cohort studies compared the AUCs of waistto-height ratio, waist circumference and body mass index in discriminating obesity-related disease and concluded that the waist-to-height ratio has superior performance over body mass index and waist circumference [8]. A higher discriminative power of the waist-to-height ratio than body mass index was also presented in other meta-analysis results based on previously conducted prospective studies [9]. Furthermore, the waist-to-height ratio was shown to be a significantly better tool than waist circumference in a meta-analysis of within-study differences in AUCs between the waist-to-height ratio and waist circumference [8]. However, the difference in the discriminative performance of body mass index, waist circumference and waist-to-hip ratio has not 
Table 4 Optimal cutoff values, Youden indices, and sensitivity and specificity of obesity indices associated with metabolic abnormalities and their components among HEXA-G participants by sex

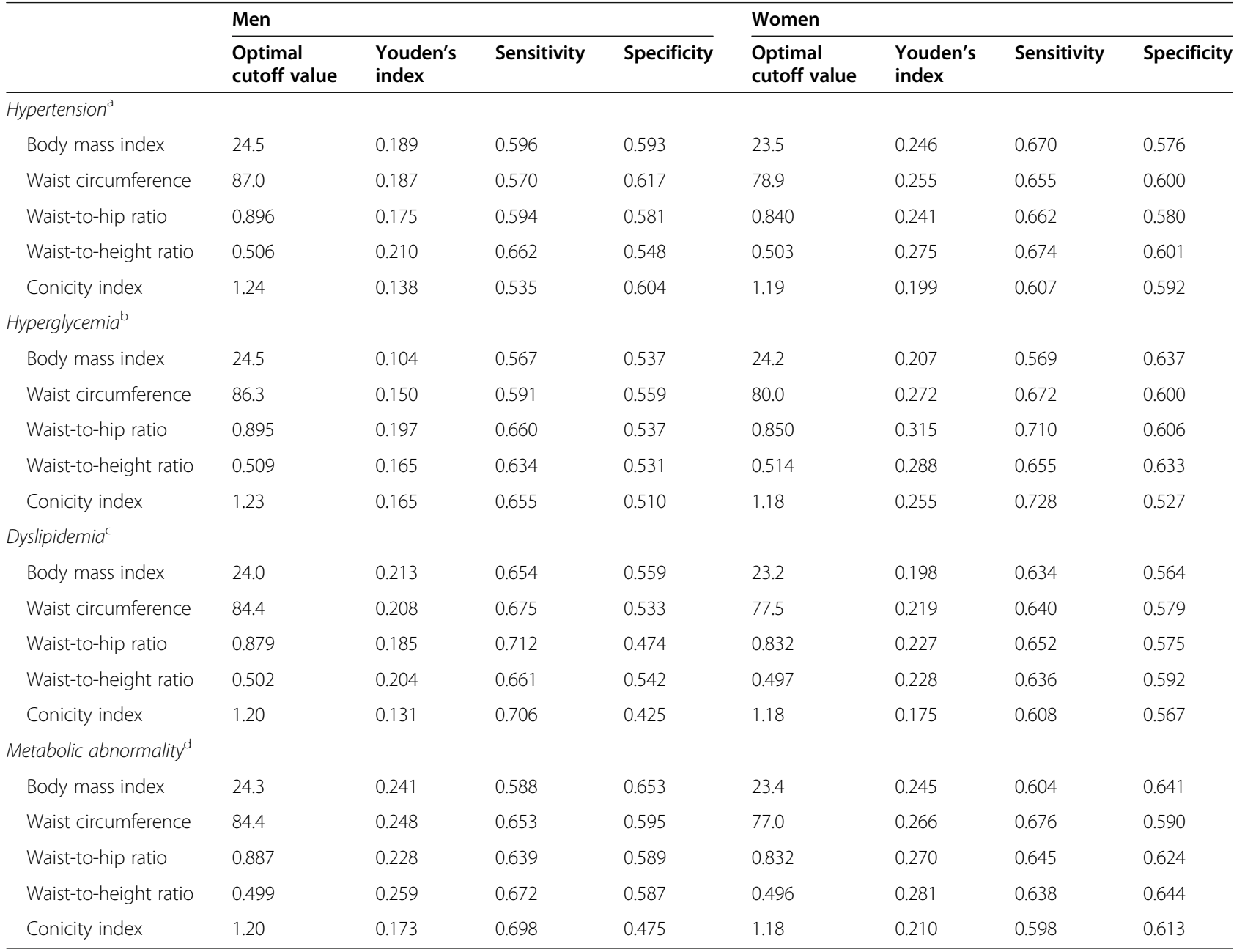

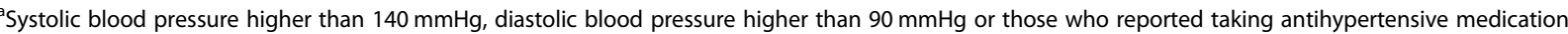
${ }^{b}$ Fasting glucose higher than $126 \mathrm{mg} / \mathrm{dL}$ or those who reported taking antidiabetic medication

${ }^{c}$ Triglyceride higher than $150 \mathrm{mg} / \mathrm{mL}$, high-density lipoprotein cholesterol lower than $40 \mathrm{mg} / \mathrm{dL}$ or those who reported taking medication for dyslipidemia

${ }^{\mathrm{d}}$ Having at least one of the aforementioned factors

shown statistical significance in the pooled analysis of over eighty thousand individual data from British cohorts [10].

The optimal cutoff values of body mass index and waist circumference from the present study were lower than previous guidelines of the WHO [6] and the National Cholesterol Educational Program (NCEP) [27]. Our results showed that body mass indices of more than $24.3 \mathrm{~kg} / \mathrm{m}^{2}$ among men and $23.4 \mathrm{~kg} / \mathrm{m}^{2}$ among women were associated with the presence of metabolic abnormalities, while the WHO recommended that obesity in Asian populations be defined as a body mass index of $25 \mathrm{~kg} / \mathrm{m}^{2}$ or higher [6]. We obtained waist circumference cutoffs of 84.4 $\mathrm{cm}$ for men and $77.0 \mathrm{~cm}$ for women, and these results are lower than the NCEP guidelines for metabolic syndrome, which defined obesity as a waist circumference of more than $90 \mathrm{~cm}$ for men and 80 $\mathrm{cm}$ for women [9]. We suggested that a lower cutoff abdominal obesity index could discriminate metabolic dysfunction in Asians. A previous prospective cohort study in Korea also described that lower waist circumference $(80 \mathrm{~cm}$ for men and $78 \mathrm{~cm}$ for women) had a better performance to predict the development of metabolic abnormalities than the NCEP guidelines [27].

This study had several limitations. First, there is an inherent limitation of temporality in the cross-sectional design. However, our results are similar to the results from prospective studies in Korea [20, 26], and we suggest that the theoretical effect of the temporality of our results is not strong. Second, it is difficult to generalize these results to young people. The study participants consisted of Koreans aged 40 to 60 years who regularly attended health screening examinations; therefore, the 
cutoff values derived from the current study may be relevant to the middle-aged Korean population only.

\section{Conclusions}

The waist-to-height ratio is the best index to discriminate metabolic abnormalities among middle-aged Koreans. The optimal cutoff of obesity indices of body mass index and waist to circumference is lower than the recommendations from the WHO and NCEP. Based on these findings, to determine obesity-related health problems in Koreans, it would be appropriate to use indices for abdominal obesity rather than general obesity and to consider a lower level of body mass index and waist circumference than the current guidelines. We hope that these results will improve the guidelines for screening populations at high risk for cardiometabolic diseases via appropriate recommendations for obesity in Korea.

\section{Abbreviations}

AUC: Area under the receiver operating characteristic curve; WHO: World Health Organization; KoGES: The Korea Genome Epidemiology Study; HEXA: Health Examinees in KoGES; HEXA-G: Health Examinees-Gem in KoGES; ROC: Receiver operating characteristic

\section{Acknowledgements}

Not applicable.

\section{Authors' contributions}

SC and AS designed this study. SC performed the statistical analyses and wrote the manuscript. AS edited the manuscript. AS, JYC, SMP, DK, and JKL were responsible for the designs of this work. All authors read, edited and approved the final manuscript.

\section{Funding}

This study was supported by the Korea Centers for Disease Control and Prevention [funding codes 2004-E71004-00, 2007-E71006-00, 2005-E7101100, 2008-E71006-00, 2005-E71009-00, 2008-E71008-00, 2006-E71001-00, 2009-E71009-00, 2006-E71004-00, 2010-E71006-00, 2006-E71010-00, 2011 E71006-00, 2006-E71003-00, 2012-E71001-00, 2007-E71004-00, and 2013E71009-00]. The funder had a role in the design of the study and data collection. We declare that the funder had no role in the analysis or writing of the manuscript.

\section{Availability of data and materials}

The datasets generated and analyzed during the current study are not publicly available due to ethical considerations of the participants' confidentiality but are available from the corresponding author upon reasonable request.

\section{Declarations}

Ethics approval and consent to participate

This study was approved by the Ethics Committee of the Korean Health and Genomic Study of the Korean National Institute of Health and the institutional review boards of all participating hospitals (IRB No. E-1503-103657). We explained the aim of the study to the study participants and obtained written informed consent.

\section{Consent for publication}

Not applicable.

\section{Competing interests}

The authors declare no conflicts of interest.

\section{Author details}

'Department of Preventive Medicine, Seoul National University College of Medicine, Seoul, Republic of Korea. ${ }^{2}$ Cancer Research Institute, Seoul National University, Seoul, Republic of Korea. ${ }^{3}$ Department of Biomedical Science, Seoul National University Graduate School, Seoul, Republic of Korea. ${ }^{4}$ Department of Family Medicine, Seoul National University Hospital, Seoul, Republic of Korea. ${ }^{5}$ Department of Family Medicine, Seoul National University College of Medicine, Seoul, Republic of Korea. ${ }^{6}$ JW LEE Center for Global Medicine, Seoul National University College of Medicine, Seoul, Republic of Korea. ${ }^{7}$ Seoul Center for Infectious Disease Control, Seoul, Republic of Korea.

Received: 14 August 2020 Accepted: 23 February 2021

Published online: 06 March 2021

\section{References}

1. Abarca-Gómez L, Abdeen ZA, Hamid ZA, Abu-Rmeileh NM, Acosta-Cazares B, Acuin C, Adams RJ, Aekplakorn W, Afsana K, Aguilar-Salinas CA, et al. Worldwide trends in body-mass index, underweight, overweight, and obesity from 1975 to 2016: a pooled analysis of 2416 population-based measurement studies in 128.9 million children, adolescents, and adults. Lancet. 2017;390(10113):2627-42.

2. GBD 2015 Obesity collaborators. Health effects of overweight and obesity in 195 countries over 25 years. N Engl J Med. 2017;377(1):13-27.

3. Dai H, Alsalhe TA, Chalghaf N, Riccò M, Bragazzi NL, Wu J. The global burden of disease attributable to high body mass index in 195 countries and territories, 1990-2017: an analysis of the global burden of disease study. PLoS Med. 2020;17(7):e1003198.

4. Willett WC, Dietz WH, Colditz GA. Guidelines for healthy weight. N Engl J Med. 1999;341(6):427-34

5. Hu FB. Obesity and mortality: watch your waist, not just your weight. Arch Intern Med. 2007;167(9):875-6.

6. World Health Organization. The Asia-Pacific perspective: redefining obesity and its treatment. Sydney: Health Communications Australia; 2000.

7. Zheng W, McLerran DF, Rolland B, Zhang X, Inoue M, Matsuo K, He J, Gupta PC, Ramadas K, Tsugane S, et al. Association between body-mass index and risk of death in more than 1 million Asians. N Engl J Med. 2011; 364(8):719-29.

8. Ashwell M, Gunn P, Gibson S. Waist-to-height ratio is a better screening tool than waist circumference and BMl for adult cardiometabolic risk factors: systematic review and meta-analysis. Obes Rev. 2012;13(3):275-86.

9. Savva SC, Lamnisos D, Kafatos AG. Predicting cardiometabolic risk: waist-toheight ratio or BMI. A meta-analysis. Diabetes Metab Syndr Obes. 2013;6: 403-19.

10. Czernichow S, Kengne A-P, Stamatakis E, Hamer M, Batty GD. Body mass index, waist circumference and waist-hip ratio: which is the better discriminator of cardiovascular disease mortality risk? Evidence from an individual-participant meta-analysis of 82,864 participants from nine cohort studies. Obes Rev. 2011:12(9):680-7.

11. Kim Y. Han B-G, the KoGES group: cohort profile: the Korean genome and epidemiology study (KoGES) consortium. Int J Epidemiol. 2016:46(2):e20.

12. Health Insurance Guide [https://www.nhis.or.kr/static/html/wbd/g/a/wbdga 0606.html].

13. Valdez R, Seidell JC, Ahn YI, Weiss KM. A new index of abdominal adiposity as an indicator of risk for cardiovascular disease. A cross-population study. Int J Obes Relat Metab Disord. 1993;17(2):77-82.

14. Wang YF, Wang QJ. The prevalence of prehypertension and hypertension among US adults according to the new joint National Committee guidelines. Arch Intern Med. 2004;164(19):2126-34.

15. Diagnosis and Classification of Diabetes Mellitus. Diabetes Care. 2014; 37(Supplement 1):S81-90.

16. Youden WJ. Index for rating diagnostic tests. Cancer. 1950;3(1):32-5.

17. R Core Team. R: A language and environment for statistical computing. Vienna: R Foundation for Statistical Computing; 2020.

18. Browning LM, Hsieh SD, Ashwell M. A systematic review of waist-to-height ratio as a screening tool for the prediction of cardiovascular disease and diabetes: 0.5 could be a suitable global boundary value. Nutr Res Rev. 2010; 23(2):247-69.

19. Lin WY, Lee LT, Chen CY, Lo H, Hsia HH, Liu IL, Lin RS, Shau WY, Huang KC. Optimal cut-off values for obesity: using simple anthropometric indices to predict cardiovascular risk factors in Taiwan. Int J Obes Relat Metab Disord. 2002;26(9):1232-8 
20. Park SH, Choi SJ, Lee KS, Park HY. Waist circumference and waist-to-height ratio as predictors of cardiovascular disease risk in Korean adults. Circ J. 2009;73(9):1643-50.

21. Shao J, Yu L, Shen X, Li D, Wang K. Waist-to-height ratio, an optimal predictor for obesity and metabolic syndrome in Chinese adults. J Nutr Health Aging. 2010;14(9):782-5.

22. Park YS, Kim JS. Association between waist-to-height ratio and metabolic risk factors in Korean adults with normal body mass index and waist circumference. Tohoku J Exp Med. 2012;228(1):1-8.

23. Pan J, Wang M, Ye Z, Yu M, Shen Y, He Q, Cao N, Ning G, Bi Y, Gong W, et al. Optimal cut-off levels of obesity indices by different definitions of metabolic syndrome in a southeast rural Chinese population. J Diabetes Investig. 2016;7(4):594-600

24. Dalton M, Cameron AJ, Zimmet PZ, Shaw JE, Jolley D, Dunstan DW, Welborn TA, AusDiab Steering C. Waist circumference, waist-hip ratio and body mass index and their correlation with cardiovascular disease risk factors in Australian adults. J Intern Med. 2003;254(6):555-63.

25. Janssen I, Katzmarzyk PT, Ross R. Waist circumference and not body mass index explains obesity-related health risk. Am J Clin Nutr. 2004;79(3):379-84.

26. Ko KP, Oh DK, Min H, Kim CS, Park JK, Kim Y, Kim SS. Prospective study of optimal obesity index cutoffs for predicting development of multiple metabolic risk factors: the Korean genome and epidemiology study. J Epidemiol. 2012;22(5):433-9.

27. National Cholesterol Education Program Expert Panel on Detection. Evaluation, treatment of high blood cholesterol in adults: third report of the National Cholesterol Education Program (NCEP) expert panel on detection, evaluation, and treatment of high blood cholesterol in adults (adult treatment panel III) final report. Circulation. 2002;106(25):3143-421.

\section{Publisher's Note}

Springer Nature remains neutral with regard to jurisdictional claims in published maps and institutional affiliations.

Ready to submit your research? Choose BMC and benefit from:

- fast, convenient online submission

- thorough peer review by experienced researchers in your field

- rapid publication on acceptance

- support for research data, including large and complex data types

- gold Open Access which fosters wider collaboration and increased citations

- maximum visibility for your research: over $100 \mathrm{M}$ website views per year

At $\mathrm{BMC}$, research is always in progress.

Learn more biomedcentral.com/submissions 